\title{
ERP Systems Implementation And Firm Performance
}

Andreas I. Nicolaou (Email: anicol@cba.bgsu.edu), Bowling Green State University Lawrence H. Bajor (Email: bajorl@cba.bgsu.edu), Bowling Green State University

\begin{abstract}
The recent wave of enterprise resource planning systems adoption represents a significant commitment of resources and has a dramatic effect on all business processes. These systems influence a firm's performance over a long-term time horizon. This study examines the effect of adoption of ERP on a firm's long-term operational performance. Financial data of companies adopting ERP systems and of a matched control group of firms were compared before and after adoption. The results from an analysis of performance differences across time periods has shown that firms adopting ERP systems have exhibited a significantly higher differential performance during the two years following the completion of the system than the control group of firms. These results provide important insights about ERP implementation.
\end{abstract}

\section{Introduction}



recent wave of information technology (IT) adoption has evolved around the adoption and use of enterprise-wide resource planning (ERP) systems (Davenport 1998). These systems allow businesses to incorporate information needs of all functional areas into a single system that captures "event" data relating all operational aspects of a business and integrate information needs of all business processes. In industry and professional reports, it is often stated that the basic drivers motivating adoption of ERP systems include: cost reduction, improved efficiency, reduced product cycle time, improved customer service and satisfaction, ability to change and configure business in response to changing market place, and enabling of ecommerce (Attaway 1999; Glover, Prawitt and Romney 1999). Since all of the above drivers could support a company's quest for competitive advantage or help in maintaining its competitive parity, an organization's decision to adopt an ERP system is considered a strategic investment decision (Cooke and Peterson 1998; Wah 2000). Such an investment represents a significant commitment of resources and has a dramatic effect on all operational aspects of a business. As a result, the need to examine the effect of ERP systems adoption on a firm's financial performance represents an important motivation for this study.

Given the nature of ERP investments, their expected benefits cannot be observed in a short period of time. ERP systems, once implemented in an organization, remain operational for a long period of time because they often serve as a basis to improve an organization's information infrastructure and allow future expansion (Shang and Seddon 2000). Evaluating the success of these investments has to consider a firm's performance over a relatively long period of time. The purpose of this study, therefore, will be to empirically examine whether the adoption of ERP systems affects a firm's long-term operational performance.

An empirical response to this question is a worthwhile pursuit because it will help enhance our understanding of the system development process in ERP systems. Past empirical studies have examined the market response to ERP system implementations (Hayes, Hunton and Reck 2001) and also measured the extent to which ERP adopting firms have realized a set of theoretically expected benefits due to ERP implementation (Poston and Grabski 2001). This study examines the differential effects of ERP adoption on long-term operational performance using an extensive sample of ERP adopting firms. This is especially important in the case of ERP systems, since a very significant investment in resources is required for their implementation, while the realization of system benefits is reported to significantly lag expectations (Benchmarking Partners 1998; Meta Group 1999; Peterson, Gelman and 
Cooke 2001). The results of this study will therefore provide useful insights to information systems professionals and users who need to justify such a significant investment in organizational resources.

\section{Review of Literature}

ERP systems are integrated systems in that they promote cooperation among groups, teamwork, process expertise and business knowledge, and help devolve authority and responsibility from management to front lines (Hammer 1999). The integrating nature of an ERP system, therefore, captures the organizational impact that is associated with the adoption and use of those systems. It is widely reported in the literature that ERP applications promise seamless integration of all information flowing through a company: accounting and financial information, human resource information, supply chain information, and customer information (Davenport 1998; Kumar and Van Hillegersberg 2000). ERP systems are thus designed to help manage organizational resources in an integrated manner.

The professional literature has been proactive in determining the types of benefits that companies might anticipate from their ERP systems and to what extent organizations had actually attained those benefits on a postimplementation basis. In a Benchmarking Partners (1998) study, respondent companies anticipated to realize both tangible and intangible benefits from the implementation of ERP systems. The most significant intangible benefits related to internal integration, improved information and processes, and improved customer service. Tangible benefits related to reduced inventory, personnel, procurement cost and the time needed close books, improved productivity, cash management and order management, and increased profitability. In assessing the extent to which they had actually attained those benefits, however, on a post-implementation basis, it was evident that they were not able to improve profitability or lower personnel, inventories, or system maintenance costs to the extent anticipated. On the other hand, respondents noted better-than-expected results in overall productivity and in order-management cycle time, as well as procurement, on-time delivery, and the ability to close financial cycles. In a more recent Conference Board study (Peterson et al. 2001), responding companies reported similar types of tangible and intangible benefits, with similar gaps in their level of benefit attainment after the implementation of the system.

Notwithstanding the fact that companies anticipate significant benefits from the implementation of their ERP systems, problems during the system implementation process can preclude an organization from realizing those anticipated benefits or even recovering the cost of the implementation effort (Davenport 1998). For example, several high profile ERP projects, such as Unisource Worldwide, Inc., FoxMeyer Drug, Dell Computer Corp., Dow Chemical, Hershey Food Cooperation, Whirlpool, and Gore-text, have failed and in some cases companies lost not only the capital invested in ERP, but also a portion of their business. As a result there is some skepticism associated with the ability of ERP projects to deliver the anticipated benefits (Bingi et al. 1999; Mabert et al. 2001), although ERP implementation is pervasive in many different types of industries (Kumar and Van Hillegersberg 2000; Mabert et al. 2000).

The Meta Group (1999) survey also reports that over a five to six year period, the average company incurred a negative return of $\$ 1.5$ million, when quantifiable cost savings and revenue gains were balanced against hardware, software, consulting and support. However, the survey admits that ERP systems do help deliver more important intangible benefits, such as better customer services. In a cross-sectional survey of 479 ERP-adopting manufacturing firms, Mabert et al. (2000) report that realized ERP implementation benefits are concentrated more in quickly providing high-quality information within the firm, without leading to immediate cost reductions. In a multiple case study analysis of fifteen ERP implementations (Mabert et al. 2001) it is furthermore confirmed that companies realize ERP benefits relating to improvements in the accuracy, availability and quality of data and to the simplification of processes. Realized returns on investment ranged between 5 and 20 percent, which were lower than anticipated, although most firms expected to improve their returns after they had fully adapted to the new system.

In considering both the evidence offered by empirical studies as well as the observations reported in industry reports, this study will examine the long-term operational benefits attained by companies that adopt ERP systems. It is therefore expected that, other things being equal, firms adopting ERP systems will outperform 
competing firms employing systems that are not integrated in nature, over the time period after initial adoption when these systems are fully implemented and put into full use in an organization. The next section describes the research method employed to collect data used in testing this proposition.

\section{Research Method}

\subsection{Sample Selection}

A two-phase process has been followed in order to identify the sample of ERP adopting firms. At the first stage, a sample of ERP adopting firms has been identified by extracting ERP implementation announcements from the Lexis-Nexis Academic Universe (News) Wire Service Reports. Firms publicly announcing an ERP implementation from January 1, 1990 through December 31, 1998, have been included in the sample. Following Hayes et al. (2001), a keyword search was employed using a combination of the search terms "implement," "convert," and "contract" with the name of each of the following ERP vendors: Adage, BAAN, Epicor, GEAC Smartstream, Great Plains, Hyperion, Intentia International, JBA International, JD Edwards, Lawson, Oracle Financials, Peoplesoft, QAD, SAP, SSA, or SCT. These search terms have yielded an initial sample of 1,825 announcements. Subsequent review of these announcements has revealed that a great number did not relate to ERP implementations or were referring to ERP implementations in non U.S. companies or just represented repeated announcements with regard to the same event. After eliminating those announcements, a total number of 332 usable announcements that related to ERP implementation projects were identified throughout the sample period. Subsequent search in the Compustat database for data availability has resulted in a useable sample of 126 firms only.

In the second phase of sample selection, the Global Disclosure database was searched for any mention of ERP system implementation in annual reports and SEC filings, including both annual filings (form 10-K) and quarterly filings (form 10-Q). The search term of "enterprise resource planning" was applied to the full text of annual reports, $10-\mathrm{Ks}$ and $10-\mathrm{Qs}$, for the time period from $1 / 1 / 1990$ to $2 / 28 / 1999$. The initial search identified a number of 1,453 documents in which the search term appeared. Each of these documents was examined individually, using the keyword-in-context facility of the Discosure database and a great number of irrelevant documents were eliminated, while in most cases there were multiple documents describing the same ERP adoption event. This selection process resulted in 131 valid ERP adoption event disclosures, while subsequent search in the Compustat database has produced a final sample of 87 useable firms, thus providing a total sample of 213 firm observations for the study. All 213 observations utilized in this study related to initial implementations of ERP systems, thus providing important information about the event adoption date.

\subsection{Matching Procedure}

Each ERP adopting firm was matched with a control (non-ERP adopting) company on both industry and size at the year preceding the ERP adoption year (time t-1). Firms were matched by the four-digit Standard Industrial Classification (SIC) code first. Second, companies were matched by size, using total assets. The selection rule was to form firm pairs within the same 4-digit SIC with the closest asset size match. There were only few instances ( $\mathrm{n}=8$ out of 213) were we had to go beyond the 4-digit SIC and select a firm using a 3-digit match. An inability to find U.S. matches for certain unique firms resulted in 4 lost firms. The list of matched firms was subsequently examined if they had any announcement or other ERP system adoption disclosure in Newswires and Annual Reports throughout year $\mathrm{t}+3$. A number of seven firms were identified and replaced.

\subsection{Performance Measurement}

There are three types of performance measures that can be used to gauge differential performance; accounting measures, market measures, and risk measures. By far, the most popular way of measuring performance is with accounting measures. Their popularity is attributed to the fact that accounting measures are publicly available and capture information on many dimensions of a firm's operations. 
Firms that are successful in implementing and using ERP systems will enjoy superior financial performance by raising revenues or decreasing costs. The anticipated benefits identified by the industry reports reviewed in the literature review section support this conclusion. Hence, traditional accounting variables are most likely to capture this change and this study will use accounting measures of performance in order to test the research hypotheses.

Among the accounting measures, ROA is the most frequently used in the strategic management literature. Although there are several limitations of accounting measures of performance, ROA has been shown to be related to several other measures of financial performance, and to be the best overall measure of financial performance (Barber and Lyon 1996). Due to the long-term nature of our tests, it is expected that companies might have used their ERP system for long enough time to realize such returns. The Benchmarking Partners report (1998) suggested that a time period of about one to two years is required for a company to attain such benefits. This supports the use of the ROA measure in this study as an overall performance measure that captures both profitability improvements due to a possible combination of cost reductions and sales growth as well as efficiency improvements due to a combination of streamlined internal operations and external supply chain efficiencies.

A noticeable reduction in raw materials and finished goods inventories should also be an expected outcome for most ERP adopting firms. If such expected efficiencies are realized there should also be a reduction in cost of goods sold as a proportion of sales, assuming selling prices are not adjusted downward when cost savings arise. The increased efficiency in business processes that results from internal integration, higher quality information, and external integration with trading partners, should produce savings in product cost as a proportion of sales. The level of integration allowed by ERP should help an adopting firm to more accurately predict inventory requirements, improve production planning and eventually reduce finished goods inventory. Therefore, a relative decrease in inventory levels between ERP adopting and non-adopting firms should be expected, thus improving inventory turnover. As a result, this study will measure financial performance using a set of five different financial indicators, including: return on assets (ROA), return on sales (ROS), the ratio of cost of goods sold over sales (COGS), the ratio of number of employees over sales (EESALES) and inventory turnover (IVT).

\section{Results}

The research proposition advanced in the study calls for a comparison between (a) the performance of ERP adopting firms pre- and post-completion and (b) between the performance of ERP adopters versus the matched group of firms. For this reason, a series of tests on mean differences were run. The results of these test results are shown in Table 1.

The first model involves the simple comparison of means in the adopting and matched firms before the ERP adoption event and is shown in Panel A of Table 1. The measures of the variables for the years t minus 3 (i.e., three years before adoption event) through $t$ minus 1 (i.e., one year before adoption event) will be averaged for both the adopting firms and their matched pairs. Note the sample size for each of these tests is slightly different. If a value was missing for either the sample or the matching firm, both were dropped from the analysis. The t-test comparison of the mean differences on each of the five performance variables produced no significant results. A non-parametric test using Wilcoxon's Z statistic also produced similar results. This is an expected result and provides additional evidence for the adequacy of our matching procedures.

Panel B of Table 1 shows a comparison of the average performance of the adopting firms across time. The test compares mean differences on average performance of the three pre-adoption years versus average performance of the two years following ERP completion. Due to the fact that ERP implementation would take at least one year, the ERP completion year was taken to be the next financial year-end after the ERP adoption year. For a firm adopting a system in 1996, for example, the completion year would be 1997 and the two year-average performance score after completion would include measures from the year-ends of 1998 and 1999 . The results of this test, as reported in the Table, were robust to alternative combinations of years such as comparison of the average of two pre-adoption with two post-completion years. The results indicate that both ROA and ROS are significantly higher on average for the adopting firms pre adoption than after the completion of ERP. The number of employees over 
sales is significantly lower after ERP completion, as is the cost of goods sold over sales ratio. While the cost of goods sold in relation to sales seems to have dropped considerably for firms after ERP completion, there was no difference for inventory turns.

Table 1: Tests On Mean Differences

Panel A: Comparison Of Means Between Sample And Matched Firms For 3 Years Before ERP Adoption

\begin{tabular}{|l|c|c|c|c|c|}
\hline Variable & $\begin{array}{c}\text { Sample Size } \\
\text { (Different on each measure } \\
\text { due to missing data in } \\
\text { Compustat) }\end{array}$ & $\begin{array}{c}\text { Adopt Firms } \\
\text { Average Value for 3 } \\
\text { Years Preceding ERP } \\
\text { Adoption Year }\end{array}$ & $\begin{array}{c}\text { Control Firms } \\
\text { Average Value for 3 } \\
\text { Years Preceding ERP } \\
\text { Adoption Year }\end{array}$ & $\begin{array}{c}\text { t-test on } \\
\text { Mean } \\
\text { Differences } \\
\text { (t-values) }\end{array}$ \\
\hline ROA & $\mathrm{n}=169$ & 4.7472 & 6.7114 & -1.334 \\
\hline ROS & $\mathrm{n}=167$ & 9.7881 & 7.5854 & 0.1940 \\
\hline Employees/Sales & $\mathrm{n}=146$ & 0.1033 & 0.0213 & -0.8243 \\
\hline Inventory Turns & $\mathrm{n}=114$ & 9.6803 & 10.2575 & -0.2774 \\
\hline COGS/Sales & $\mathrm{n}=129$ & 0.6727 & 0.7169 & -1.1035 \\
\hline
\end{tabular}

Panel B: Comparison Of Means Of Sample Firms Across Time; Before ERP Adoption and After ERP Completion

\begin{tabular}{|l|c|c|c|c|c|}
\hline \multicolumn{1}{|l|}{} & $\begin{array}{c}\text { Sample Size } \\
\text { (Different on each measure } \\
\text { due to missing data in } \\
\text { Compustat) }\end{array}$ & $\begin{array}{c}\text { adopt firms } \\
\text { Average Value for 3 } \\
\text { Years Preceding ERP } \\
\text { Adoption Year }\end{array}$ & $\begin{array}{c}\text { Adopt Firms } \\
\text { Average Value for 2 } \\
\text { Years Following ERP } \\
\text { Completion Year }\end{array}$ & $\begin{array}{c}\text { t-test on } \\
\text { Mean } \\
\text { Differences } \\
\text { (t-values) }\end{array}$ \\
\hline ROA & $\mathrm{n}=130$ & 6.8700 & 2.6900 & $-2.9947^{*}$ \\
\hline ROS & $\mathrm{n}=119$ & 11.2660 & 4.0772 & $-1.7618^{*}$ \\
\hline Employees/Sales & $\mathrm{n}=129$ & 0.0956 & 0.0799 & $3.6477^{*}$ \\
\hline Inventory Turns & $\mathrm{n}=113$ & 9.8425 & 10.7268 & -0.9788 \\
\hline COGS/Sales & $\mathrm{n}=129$ & 0.6648 & 0.4363 & $19.7291^{*}$ \\
\hline
\end{tabular}

Panel C: Comparison Of Means Between Sample And Matched Firms; After ERP Completion

\begin{tabular}{|l|c|c|c|c|c|}
\hline Variable & $\begin{array}{c}\text { Sample Size } \\
\text { (Different on each measure } \\
\text { due to missing data in } \\
\text { Compustat) }\end{array}$ & $\begin{array}{c}\text { Adopt Firms } \\
\text { Average Value for 2 } \\
\text { Years Following ERP } \\
\text { Completion Year }\end{array}$ & $\begin{array}{c}\text { Control Firms } \\
\text { Average Value for 2 } \\
\text { Years Following ERP } \\
\text { Completion Year }\end{array}$ & $\begin{array}{c}\text { t-test on } \\
\text { Mean } \\
\text { Differences } \\
(\boldsymbol{t} \text {-values })\end{array}$ \\
\hline ROA & $\mathrm{n}=140$ & 2.6545 & 0.6855 & 1.5745 \\
\hline ROS & $\mathrm{n}=138$ & 3.6955 & -4.6542 & $1.8789^{*}$ \\
\hline Employees/Sales & $\mathrm{n}=129$ & 0.0814 & 0.0713 & 0.4197 \\
\hline Inventory Turns & $\mathrm{n}=125$ & 12.4244 & 12.2977 & 0.0197 \\
\hline COGS/Sales & $\mathrm{n}=139$ & 0.4254 & 0.6858 & $-9.920^{*}$ \\
\hline
\end{tabular}

Level of Significance: $* p<.05$

Panel C of Table 1 presents results on the differences on the means between the adopting (sample) firms and the matching firms in the post ERP completion period. Although the ROA for the sample firms is higher relative to control firms, the test parameter is not significant at any traditionally accepted level. The results on ROS, nevertheless, demonstrate a significant relative improved performance of ERP adopting firms versus the control firms in the two years after completion of ERP. A corroborating result relates to the significant relative improved performance of ERP adopting firms versus the control firms on the costs of goods sold over sales measure. The other measures of the number of employees over sales and inventory turns did not exhibit significant differences 
between adopting and control firms after ERP completion. All tests were also replicated using a non-parametric statistic with similar results.

\section{Discussion}

The research proposition developed in the theoretical section of the paper predicted that a firm's performance, as compared to a matched control firm, after the adoption and use of an ERP system would be significantly higher than its own performance prior to the adoption of the ERP system. This proposition was tested using data for one and two years after the completion of an ERP system. It is especially important to note that the time of completion of an ERP system determines the time-to-benefit, that is, the time that is required by a company to adjust to the new system and train its users so that anticipated benefits can materialize. It was therefore especially important that the measurements in this study were performed during a time period where an ERP adopting firm would be expected to realize benefits.

In general, we find no difference between the performance of the adopting firms and the matching firms in the pre-adoption environment. The absence of any differences is indicative of the comparability of the matched and adopting firm pairs. In comparing the ERP adopting firms with themselves in the pre-adoption time frame we find that in the post-completion time frame, ERP adopting firms report lower ROA, lower ROS, lower COGS over sales and a lower number of employees over sales. With the exception of the COGS and EESALES, these results could be an artifact of the economy. On a post-completion time frame, the sample firms were also found to be significantly superior to their matched pairs with regard to relative profitability and relative costs of goods sold over sales. In addition, the adopting firms were not worse than the matching firms with regard to any other performance measures. Since the post-ERP completion time frame comparison is made between adopting and matching firms for the same years, any effects due to general economic conditions are being controlled. These results, although limited, are significantly in favor of ERP adoption.

The results reported in this study are also consistent and complement other studies examining ERP performance effects (Poston and Grabski 2001) and studies that examined market reactions to ERP adoption event announcements (Hayes et al. 2001). Considering the results of those studies that reported significant reactions to such announcements, the expectation would be that there should exist an increase in future returns. The main strength of this study is that it employs a large enough sample to provide support for such a conclusion.

A limitation of this study relates to that the sample of experimental firms used only included firms that voluntarily disclosed ERP implementation announcements, either through business newswires or through their annual reports. As a result, the sample might be biased. In addition, the study did not control for some potentially important implementation or organizational characteristics. For example, the specific vendor of ERP software chosen or the specific types of applications installed in an enterprise suite might affect a firm's ability to realize certain types of benefits and thus might differentially affect its financial performance.

In conclusion, this study has provided important insights for professionals in the field who might be faced with the task of justifying new investments in ERP systems. In addition, researchers can use these somewhat encouraging results in order to develop formal measures of ERP benefits and associate those with specific financial performance indicators of ERP system implementation success. Most likely, future research will examine additional control variables that could influence ERP performance outcomes as well as use a more qualitative approach to develop measures of success for enterprise system applications.

\section{References}

1. Attaway, M.C. 1999. "Billing risks", Internal Auditor (August): 43-47.

2. Barber, B.M. and J.D. Lyon. "Detecting Abnormal Operating Performance: The Empirical Power and Specification of Test Statistics", Journal of Financial Economics, Vol. 41 No. 3, July 1996, pp. 359-399.

3. Benchmarking Partners. 1998. ERP's Second Wave: Maximizing the Value of ERP-Enabled Processes. Cambridge, MA. 
4. Bingi, P., Sharma, M. and Godla, J. 1999. "Critical factors affecting an ERP implementation", Information Systems Management, 16 (3), 7-.

5. Cooke, D. P., and W. J. Peterson. 1998. SAP Implementation: Strategies and Results. The Conference Board Inc., New York, NY.

6. Davenport, T.H. 1998. "Putting the enterprise into the enterprise system", Harvard Business Review 76 (July/August): 121-131.

7. Glover, S.M., D.F. Prawitt, and M.B. Romney. 1999. “Implementing ERP”, Internal Auditor (February): 40-47.

8. Hammer, M. 1999. “Up the ERP evolution”, Information Week (February 8): 186-187.

9. Hayes, D.C., J.E. Hunton, and J.L. Reck. 2001. "Market reaction to ERP implementation announcements", Journal of Information Systems 15 (Spring): 3-18.

10. Kumar, K. and J. Van Hillegersberg, Guest Editors. 2000. "ERP: Experiences and evolution", Communications of the ACM 43 (April): 23-26.

11. Mabert, A. M., A. Soni and M.A. Venkataraman. 2000. "Enterprise Resource Planning survey of US manufacturing firms", Production and Inventory Management Journal, 41(2), 52-58.

12. Mabert, V.A., A. Soni and M.A. Venkataramanan. 2001. "Enterprise resource planning: Common myths versus evolving reality", Business Horizons (May-June): 69-76.

13. META Group. 1999. Enterprise Resource Management (ERM) Solutions and Their Value. Stamford, CT.

14. Peterson, W.J., L. Gelman and D.P. Cooke. 2001. "ERP Trends", New York, NY: The Conference Board; Report 1292-01-RR.

15. Poston, R. and S. Grabski. 2001. "Financial impacts of enterprise resource planning implementations", International Journal of Accounting Information Systems 2 (4): 271-294.

16. Shang, S., and P. Seddon. 2000. "A comprehensive framework for classifying benefits of ERP systems", Proceedings AMCIS, 2000: 1005-1014.

17. Wah, L. 2000. "Give ERP a chance”, Management Review (March): 20-24.

Notes 
Notes 